\title{
Research Status and Development Trend of Pantograph Contact Strip Materials
}

\author{
SHANG Feng ${ }^{1,2, a}$ SUN Wei ${ }^{1, b}$ QIAO Bin ${ }^{1,2, c} \quad$ HE Yi-qiang ${ }^{1, d}$ and LI Hua-qiang, \\ ${ }^{1}$ School of Mechanical Engineering, Huaihai Institute of Technology, Lianyungang Jiangsu 222005, \\ China \\ 2 Jiangsu Key Laboratory of Large Engineering Equipment Detection and Control,Xuzhou Institute of \\ Technology, Xuzhou Jiangsu 221111, China \\ ashf184518@163.com, ${ }^{\mathrm{b}} 1137507928 @ q q . c o m,{ }^{\mathrm{c}} \mathrm{Qiao6636@126.com,}$ \\ dant210@126.com, ${ }^{\mathrm{e}}$ lhq6729@163.com
}

\begin{abstract}
The pantograph contact strip is a sliding current collecting component used in electric locomotive. Its performance is an important factor restricting the development of electrified railways toward high speed. This paper makes an introduction of the new developing composite material strips, points out the advantages and disadvantages of various materials, their limiting factors during using or bottlenecks in $R \& D$ and production, and gives prospect to the future development of pantograph contact strip materials in the end.
\end{abstract}

\section{Introduction}

As a component of current collection by friction, the pantograph contact strip is required to have good anti-friction, wear resistance and self-lubrication, as well as good conductivity and impact resistance. Since electric locomotives were put into operation, theory research and application study on pantograph contact strip materials have never ceased. Developed countries like Japan, Germany and France have made important achievements in the study of pantograph contact strips [1]. Currently, pantograph contact strip materials have developed from the original pure metal contact strip and powder metallurgy contact strip to the current mostly applied pure carbon contact strip and metal-impregnated carbon contact strip. To meet the new demand, composite material contact strip develops rapidly $[2,3]$.

\section{Research Status of New Material Contact Strips}

The electric locomotives are developing towards high speed and its operating environment is increasingly complicated and diversified. This presents harsher performance requirements on pantograph contact strips, and makes the limitations of conventional pantograph contact strips in using standing out gradually. Therefore, developing new contact strip material combining various excellent properties becomes a hot research

*Corresponding author:shf184518@163.com 
direction of each country. Composite material can be made by combining multiple materials with different properties according to the requirements of target material in order to meet the special requirements for use. Thus, it grows into a popular research material for contact strip $[4,5]$. Composite materials for contact strip with greater results at current studies are carbon series composite materials and $\mathrm{Ti}_{3} \mathrm{SiC}_{2}$ conductive ceramic series composite materials.

\section{Research Status of Carbon/carbon Fiber Composite Material Contact Strip}

Carbon/carbon fiber composite material contact strip are commonly made by hot press molding with thermosetting resin as the matrix, copper as the conductive phase and carbon fiber as the reinforcing phase[6,7]. This contact strip material has good anti-friction, wear resistance and self-lubrication with low density, high strength and good high temperature resistance. But this material takes long production cycle and high cost $[8,9]$. Yuan Hua, etc. make carbon fiber reinforced pantograph contact strip by hot pressing technique with continuous carbon fiber and short carbon fiber as the reinforcing phase. Under the condition of constant load $70 \mathrm{~N}, \mathrm{v}<20 \mathrm{~m} / \mathrm{s}$ and $\mathrm{J}<80 \mathrm{~A} / \mathrm{cm}^{2}$, the current-carrying efficiency of this strip is higher than $75 \%$, but as current density and sliding speed increases, current-carrying efficiency will fall. When the current density $\mathrm{J}=80 \mathrm{~A} / \mathrm{cm}^{2}$, the current-carrying efficiency will increase obviously along with the increase of loading [10]. Tsuchiya Hiroshi, etc. adopt the method of pre-forming fiber strand. First, bind up over ten thousand pieces of carbon fibers into one strand. Add fine carbon and metal powder on fiber strand. Wrap the fiber strand with resin to form into a piece of carbon fiber strand with the diameter of about $2 \mathrm{~mm}$. Use the fiber strands and resin filaments to weave a plain fiber cloth. Then laminated heating and flat pressing weaved cloths alternately. After sintered at $1200{ }^{\circ} \mathrm{C}$ and impregnated with copper alloy, this type of carbon fiber contact strip composite material is finally made. Carbon/carbon fiber composite material made by this method has lower cost and higher strength. It can be directly fixed with bolts without guard board added. After test running $100,000 \mathrm{~km}$, bolt threads have no rupture or looseness [11].

\section{Research status of carbon/metal fiber composite material contact strip}

Carbon/metal fiber composite material is made by sintering after cold pressing or hot pressing, with carbon as the matrix, and metal powder, metal fiber, metal net or their mixture as the reinforcer which is distributed evenly throughout the carbon matrix. The conductivity and impact resistance of this type of contact strip is better than metal-impregnated carbon contact strip. But the scope of metal distribution is larger in this contact strip, which will cause larger wear to overhead copper contact line. Further, once there is reinforcer damage, the overall conductive property of contact strip will drop dramatically [12]. Xu Lixin, etc. get contact strip test sample by first fully mixing graphite powder, fine copper powder and phenol-formaldehyde resin into paste adhesive, coating it onto T300 carbon fiber cloth with meshes, making powders filling mesh gaps, then tiling one layer fine copper net, stacking in turn to required thickness, hot pressing and curing at $180^{\circ} \mathrm{C}, 60 \mathrm{MPa}$, getting blank, impregnating phenol-formaldehyde resin at $6 \mathrm{MPa}$, and finally drying. This strip's resistivity can be lowered to $6.1 \mu \Omega \cdot \mathrm{m}$, flexure strength reaches $117 \mathrm{MPa}$ and impact toughness reaches $44.1 \mathrm{~J} / \mathrm{cm}^{2}[13]$. 


\section{Research status of $\mathrm{C} / \mathrm{Cu}$ composite material contact strip}

$\mathrm{C} / \mathrm{Cu}$ composite material is an umbrella name for $\mathrm{C}$ (carbon fiber, graphite fiber, graphite)/copper based composite materials. This material has not only high strength and good toughness, but also good self-lubrication and electrical and thermal conductivity, thus is an excellent sliding conductivity material [14]. But $\mathrm{Cu}$ and $\mathrm{C}$ doesn't wet mutually or react even at high temperature. Therefore, improving the surface wettability of copper matrix and carbon matrix is the key for preparing this composite material. Currently, the common used surface treatment process is adopting the method of electroless plating or electroplating to plate copper on the surface of carbon matrix. The processes of using carbon matrix with plated copper to prepare $\mathrm{C} / \mathrm{Cu}$ composite material have various methods, such as powder metallurgy, hot pressing sintering, and hot-pressing diffusion bonding, among which powder metallurgy is mostly used [15]. Li Xuefei, etc. get test sample by mixing evenly in certain proportion the self-made graphite powder with particle size of $45 \mu \mathrm{m}$ with common graphite powder and copper powder, putting into mold, cold pressing it with pressure of $380 \mathrm{MPa}$ for $3 \mathrm{~min}$ to get contact strip green body, sintering the green body at $830^{\circ} \mathrm{C} \sim 910^{\circ} \mathrm{C}$ in electric furnace, and finally re-pressing it with $360 \mathrm{MPa}$. Tests show that the friction coefficient copper plated graphite composite material is higher than that of non-copper plated graphite composite material, but the hardness and specific conductivity of the former is larger than that of the latter. The maximum hardness of the former is 45.72HBS and its conductivity is 52.5 (\%IACS) [16].

\section{Research status of Ti3SiC2 material contact strip}

$\mathrm{Ti}_{3} \mathrm{SiC}_{2}$ material is a new ceramic material system and was first made by Jeitschko and Nowotny with the method of chemical vapor deposition in 1970s [17]. This material has not only electrical conductivity, thermal conductivity and easy machining similar to metal material, high temperature resistance, oxidation resistance, wear resistance and light mass similar to ceramic material, but also good self-lubrication. It is regarded as having great guiding significance for solving the wear and friction, arc burning erosion and coupling damage and other problems on pantograph contact strip [18]. Lu Jinrong, etc. uses three different raw material ratios, $\mathrm{Ti} / \mathrm{Si} / \mathrm{C}, \mathrm{TiC} / \mathrm{Si} / \mathrm{C}$ and $\mathrm{TiH}_{2} / \mathrm{Si} / \mathrm{TiC}$, and respectively adopts three different synthesis methods, to prepare high purity $\mathrm{Ti}_{3} \mathrm{SiC}_{2}$ powder. Test results show the raw material with molar ratio of $\mathrm{TiH}_{2}: \mathrm{Si}: \mathrm{TiC}=1: 1.25: 1.8$ at $1400^{\circ} \mathrm{C} \sim 1500^{\circ} \mathrm{C}$ can make $\mathrm{Ti}_{3} \mathrm{SiC}_{2}$ powder with purity over $95 \%$ [19]. Currently, the preparation technique of this material in the lab is mature. But there's a series of industrial technology transfer problems needed to solve for this material to become the preparation material for pantograph contact strip.

\section{The Development Trend of Pantograph Contact Strip Materials}

Pure carbon contact strips are commonly used at present. Although its abrasion to overhead contact lines is small, the specific conductivity of its own is a little high and mechanical strength is low, unable to fully satisfy the demands of high-speed locomotive development. $\mathrm{C} / \mathrm{Cu}$ composite material has excellent electrical properties and impact resistance, but its required copper plated graphite powder doesn't have mass production technology. The overall properties of carbon/metal composite material is better than metal-impregnated carbon contact strip. But once there is reinforcer damage, its properties will drop dramatically. For $\mathrm{Ti}_{3} \mathrm{SiC}_{2}$ ceramic series material, though it has excellent properties, there lacks industrial production technology and vast basic researches are needed. On the contrary, carbon/carbon fiber composite material contact strip has good 
anti-friction, wear resistance and self-lubrication, with small density, high strength and high temperature resistance. In particular, the carbon fiber 3-D braiding carbon series composite material contact strip is not only with good operational performance, but with lower cost. It will become the contact strip material mainly studies in the period ahead.

\section{Acknowledgement}

The research described in this publication was made possible by financial support of the open Foundation of Jiangsu Key Laboratory of Large Engineering Equipment Detection and Control(No.JSKLEDC201401), the research project of " 521 high level personnel training project" of Lianyungang.

\section{References}

1. Yuan Hua. Preparation and Performance and Anti-wear Mechanism of Carbon Fiber Reinforced Contact Strip. Shandong University, 2013. (writing in Chinese)

2. $\mathrm{Qu}$ Chunyu, Lu Zongkui. Introduction to the Development Trend of Electric Locomotive Pantograph Slide. Carbon, (3) (2008), pp. 45-48. (writing in Chinese)

3. Min Yong, Ge Jiping, Zhao Hong. Development Overview of Electric Locomotive Pantograph Slide. China Science and Technology Information, Vol. 2(22) (2005), pp. 100. (writing in Chinese)

4. Liu Daochun. Status and Development Trend of Complex Materials in High and New Technology. Chemical Industry, Vol. 30(9) (2012), pp. 33-37. (writing in Chinese)

5. Kong Lingmei, Zheng Wei, Gao Quanxi, etc. Military and Civilian Integration in Composite Material Technology// Proceedings of The $14^{\text {th }}$ Session of the $15^{\text {th }}$ Annual Meeting of China Association for Science and Technology: Defence Science \& Technology Industry Civil-military Integration Development Forum. 2013. (writing in Chinese)

6. Yuan H, Wang C G, Lu W B, et al. Preparation and Tribological Behavior of Carbon Fiber Reinforced Pantograph Slide Plate. Advanced Materials Research, 430(2012), pp. 378-382.

7. Z. H. Chen, C. J. Tu, D. Chen, et al. Preparation and tribological investigation of resin-matrix contact strip with variable current. Materials Science \& Technology, Vol. 25(5) (2009), pp. 607-613.

8. Liu Jianjun, Zhu Bo, Wang Chengguo. Development of Carbon Fiber Composites for the Pantograph Slide Slates of the Electric Locomotive. Engineering Plastics Application, Vol. 31(8) (2003), pp. 39-41. (writing in Chinese)

9. Tu C, Chen Z, Xia J. Thermal Wear And Electrical Sliding Wear Behaviors Of The Polyimide Modified Polymer-Matrix Pantograph Contact Strip. Tribology International, Vol. 42(6) (2009), pp. 995-1003.

10. Yuan Hua, etc. Preparation and Tribological Properties of Carbon Fiber Reinforced Contact Strip// Proceedings of The $19^{\text {th }}$ Fiber Reinforced Plastics/Composites Academic Exchange. (2012), pp. 115-119. (writing in Chinese)

11. Tsuchiya Hiroshi. The application of $\mathrm{C} / \mathrm{C}$ composite material on pantograph slider Foreign Locomotive \& Rolling Stock Technology. Foreign Locomotive \& Rolling Stock Technology,(5) (2010), pp. 19-22. (writing in Chinese)

12. Pan Lianming, Zhang Guorong, Qian Zhongliang, etc. Pantograph Slide Plate for Electric Locomotive. Locomotive \& Rolling Stock Technology, (3) (2001), pp. 1-4. (writing in Chinese)

13. Xu Lixin, Qiang Xiaohu, Shi Xueting, etc. Study on Preparation and Properties of $\mathrm{CF} / \mathrm{C} / \mathrm{Cu}$ Composites. Lanzhou Jiaotong University Journal, Vol. 31(6) (2012), pp. 
118-122. (writing in Chinese)

14. Han Shaochang, Xu Zhongyu. Researching Progress of $\mathrm{C} / \mathrm{Cu}$ Matrix Composites. Materials for Mechanical Engineering, 23(6) (1999), pp. 6-8. (writing in Chinese)

15. Yang Zhenghai, Zhang Yongzhen, Chen Fuxiao, etc. Overview of $\mathrm{Cu}-\mathrm{C}$ Sliding Contact Materials with Electrical Current Produced by Powder Metallurgy. Materials Review, Vol. 26(3) (2012), pp. 106-110. (writing in Chinese)

16. Li Xuefei. Research on Preparation and Tribological Properties of Copper Matrix Graphite Composites with Electric Current. Henan University of Science and Technology, 2012. (writing in Chinese)

17. Tu Chuanjun, Chen Zhenhua, Chen Gang, etc. Current Status and Development of Carbonic System Pantograph Strip for Electric Locomotive. Carbon Techniques, Vol. 26(4) (2007), pp. 23-29. (writing in Chinese)

18. Zhai Hong-xiang, Wang Chang-an. Application of $\mathrm{Ti}_{3} \mathrm{SiC}_{2}$ materials in contact strips of pantograph. Electric Drive for Locomotives, (z1)(2003), pp. 43-45. (writing in Chinese)

19. Lu Jin-rong, Zhou Yang, Sun Jian-jun, etc. Preparation of High-purity $\mathrm{Ti}_{3} \mathrm{SiC}_{2}$ and Its Reaction Mechanisms// 2010 China Material Seminar. 2010. (writing in Chinese) 